\title{
INFLUENCE OF 627 NM WAVELENGTH LIGHT EMITTING DIODE PHOTOTHERAPY ON SECONDARY INTENTION WOUND HEALING
}

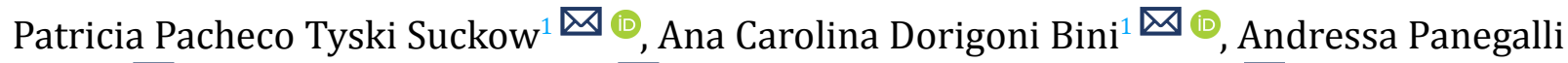

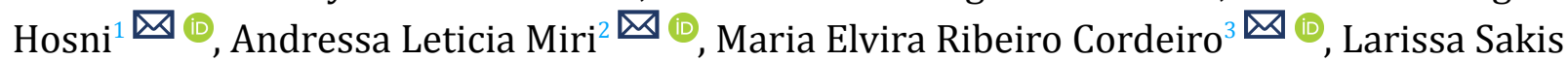

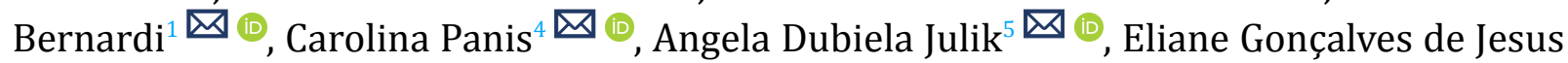

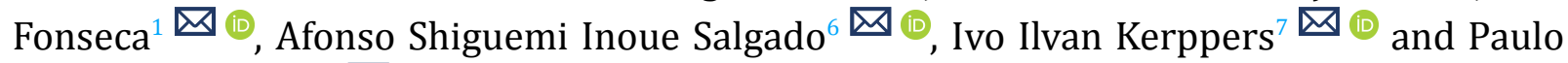
Renato de Oliveira $^{1}$ (1)

\footnotetext{
${ }^{1}$ Post Graduation Program in Pharmaceutical Sciences. Department of Pharmacy, Midwest State University - UNICENTRO, Guarapuava, PR, Brazil

${ }^{2}$ Post Graduation Program in Rehabilitation Sciences, State University of Londrina, Londrina, PR, Brazil

${ }^{3}$ Pharmacy Student, Department of Pharmacy, Midwest State University - UNICENTRO, Guarapuava, PR, Brazil

${ }^{4}$ Professor of Immunology at the State University of West Paraná, Head of the Laboratory of Tumor Biology, performing research focused on tumor biology, inflammation and redox signaling, Brazil

${ }^{5}$ Post Graduation Program in Community Development, Midwest State University - UNICENTRO, Guarapuava, Brazil

${ }^{6} \mathrm{PhD}$ in Biomedical Engineering, Chief Science Officer of Natural Quanta LLC, and the Integrative Health School, Orlando, FL, Brazil

${ }^{7}$ Laboratory of Neuroanatomy and Neurophysiology, Midwest State University - UNICENTRO, Guarapuava, PR, Brazil
}

Received 26 May 2021

Accepted 11 June 2021

Published 30 June 2021

Corresponding Author

Patricia Pacheco Tyski Suckow, pat

ysuko@hotmail.com

DOI $10.29121 /$

granthaalayah.v9.i6.2021.3983

Funding: This research received no specific grant from any funding agency in the public, commercial, or not-for-profit sectors.

Copyright: (C) 2021 The Author(s). This is an open access article distributed under the terms of the Creative Commons Attribution License, which permits unrestricted use, distribution, and reproduction in any medium, provided the original author and source are credited.

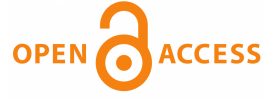

\section{ABSTRACT}

Background: The use of photobiomodulation can be effective in the healing of tissues, highlighting the use of LED in tissue repair. Was evaluated the effect of $627 \mathrm{~nm}$ wavelength LED irradiation on VEGF- $\alpha$ and TGF- $\beta 1$ expressions in a model of secondary intention wound healing.

Methods: The evaluations were performed using a dorsal puncture model and the sample consisted of 120 Wistar rats, randomly divided into LED groups submitted to 3, 7, 14 and 21 irradiation treatment for $100 \mathrm{~s}, 7 \mathrm{~J} / \mathrm{cm} 2$, and control groups. Histological analysis, immunohistochemistry and contraction of the lesion were performed.

Results: LED irradiation led to effective wound regeneration results. Similar effects were obtained with vascular, exudative, and proliferative phenomena. VEGF and TGF- $\beta 1$ levels were increased in LED-treated groups with initial treatments. Collagen analysis revealed that LED-treated groups levels were increased on days 14- and 21 of the treatments. An acceleration in tissue regeneration was observed in LED treated groups. Macroscopically visible results showing a complete healing process was evident after 14 days of treatment.

Conclusion: $627 \mathrm{~nm}$ LED irradiation effectively accelerated wound healing leading complete closure of the skin in a shorter time compared to control group. 
Keywords: Wound Healing, LED, Phototherapy, Grow Factor, Transformation Factor, Secondary Intention

\section{INTRODUCTION}

The wound healing process is a complex and dynamic mechanism that involves several factors to achieve the tissue repair, and it happens in 4 phases: hemostasis, inflammation, proliferation and remodeling Alerico et al. (2015), Otterço et al. (2018), Patrulea et al. (2015), Singh et al. (2016). It demands a well-orchestrated integration of biological and molecular events of cell migration and proliferation, deposition of extracellular matrix, angiogenesis and remodeling Isaac et al. (2010).

A deficiency in this process results in chronic wounds and among many factors that contribute to that is the compromising of the cytokine production and angiogenesis reduction Isaac et al. (2010).

A factor of great importance for the process of healing to be efficient is TGF$\beta 1$, which is involved in almost every phase of healing, amplifying the migration of inflammatory cells, stimulating angiogenesis, formation of granulation tissue, reepithelization, and increasing the deposition of collagen III and I Campos et al. (2007).

Another important factor is the VEGF- $\alpha$, secreted during proliferation phase, with the function of forming new blood vessels, which are necessary for synthesis, deposition and organization of the granulation tissue for the final phases Mendonça et al. (2009).

Treatments such as photobiomodulation have been the focus of several studies aiming for tissue healing, for it is less invasive, shows better aesthetic results and a minimal scar formation, besides, using LED (Light Emitting Diode) as a light source has a more affordable cost De and Martins (2019), de Alencar Fernandes Neto et al. (2019).

Studies have shown that red LED (610-760nm) treatments resulted in speeding the wound healing due to a mitigation of the inflammatory response, increasing of the proliferation of fibroblasts, stimulation of angiogenesis and reepithelization, increasing the collagen synthesis, and analgesic effects Adamskaya et al. (2011), Kim et al. (2013). Vieira Vieira et al. (2020) also reports that the cell multiplication is one of the main activities of LED in the red wavelength, suggesting that it may be a promising alternative for wound healing, however, there are few studies that effectively prove the physiological effects of LED on skin and a consensus has not been reached concerning the ideal irradiation parameters.

Therefore, the objective of this study was to evaluate the effects of LED wavelength $627 \mathrm{~nm}$ treatments, with a $7 \mathrm{~J} / \mathrm{cm}^{2}$ for 100 s dose on the expression of VEGF- $\alpha$ and TGF- $\beta 1$ on the healing of second intention wounds. 


\section{MATERIALS AND METHODS}

\section{ETHICS}

The present study was approved under protocol \#.015/2016 by the Ethics Committee on Animal Studies of the Midwestern Parana State University (UNICENTRO).

\section{SAMPLING}

A total of 120, two-month-old, Wistar Rattus Norvegicus males, weighing between 200 and 250 grams were obtained from the State University of Londrina - UEL-PR. The animals were housed at UNICENTRO's bioterium three per box, with free access to water and food, at $23 \pm 1{ }^{\circ} \mathrm{C}$ and under a 12-hour light/dark cycle.

\section{EXPERIMENTAL GROUPS}

Animals were divided into two main groups: Control and LED, each subdivided into 4 groups with 15 rats each. Skin lesion was performed on day 0 in all groups.

Control Group Day 3 (C3): no treatment for 3 days and euthanasia performed on the $4^{\text {th }}$ day.

Control Group Day 7 (C7): no treatment for 7 days and euthanasia performed on the $8^{\text {th }}$ day.

Control Group Day 14 (C14): no treatment for 14 days and euthanasia performed on the $15^{\text {th }}$ day.

Control Group Day 21 (C21): no treatment for 21 days and euthanasia performed on the $22^{\text {nd }}$ day.

LED Group Day 3 (L3): treatment with $627 \mathrm{~nm}$ LED at the dose of $7 \mathrm{~J} / \mathrm{cm}^{2}$ and euthanasia performed on the $4^{\text {th }}$ day.

LED Group Day 7 (L7): treatment with $627 \mathrm{~nm} \mathrm{LED} \mathrm{at} \mathrm{the} \mathrm{dose} \mathrm{of} 7 \mathrm{~J} / \mathrm{cm}^{2}$ and euthanasia performed on the $8^{\text {th }}$ day.

LED Group Day 14 (L14): treatment with $627 \mathrm{~nm}$ LED at the dose of $7 \mathrm{~J} / \mathrm{cm}^{2}$ and euthanasia performed on the $15^{\text {th }}$ day.

LED Group Day 21 (L21): treatment with $627 \mathrm{~nm}$ LED at the dose of $7 \mathrm{~J} / \mathrm{cm}^{2}$ and euthanasia performed on the $22^{\text {nd }}$ day.

\section{EXPERIMENTAL TRIAL}

Animals were previously anesthetized with $80 \mathrm{mg} / \mathrm{kg}$ of ketamine hydrochloride and $15 \mathrm{mg} / \mathrm{kg}$ of xylazine hydrochloride. A dorsal region trichotomy, approximately $4 \mathrm{~cm}$ wide and $6 \mathrm{~cm}$ long, was performed between the fourth and twelfth vertebra after checking the anesthetic status of the animal by manual compression of the tail lower third. Immediately afterwards, an $8 \mathrm{~mm}$ hole puncher was used to produce an approximately $1 \mathrm{~mm}$ deep wound.

\section{LIGHT EMITTING DIODE (LED) IRRADIATION}

The LED devices used in this study consisted of seven $627 \mathrm{~nm}$ LEDs ( $5 \mathrm{~mm}$ diameter Superbright Led model \# RL5- R12008). The LEDs were geometrically positioned in a polyvinyl chloride (PVC) platform to focus light into a single area to obtain useful irradiation intensities for a clinical application in phototherapy. A spacer inside the PVC device projected an irradiation area of $1 \mathrm{~cm}^{2}$ on the sample. The output power of the device measured using a Thorn Labs model PM100D optical wattmeter was of 
$70 \mathrm{~mW}$ at a wavelength of $627 \mathrm{~nm}$ Kerppers et al. (2015).

Irradiation was punctual and perpendicular to the skin surface during 100s for each treatment, corresponding to a dose of $7 \mathrm{~J} / \mathrm{cm}^{2}$. Each treated group received irradiations once a day for $3,7,14$, and 21 days, accordingly, with total energy densities of $21 \mathrm{~J} / \mathrm{cm}^{2}, 49 \mathrm{~J} / \mathrm{cm}^{2}, 98 \mathrm{~J} / \mathrm{cm}^{2}$ and $147 \mathrm{~J} / \mathrm{cm}^{2}$. Irradiation was conducted shortly after induction of the injury.

\section{ANALGESIA}

As a precautionary measure, all animals received $50 \mathrm{mg} / \mathrm{kg}$ tramadol orally for 7 days at every $12 \mathrm{~h}$ dos Santos et al. (2020).

\section{EUTHANASIA}

Animals were euthanized at the end of each treatment period. They were previously anesthetized before receiving a lethal dose of $175 \mathrm{mg} / \mathrm{kg}$ of intraperitoneal Pentobarbital. Death was confirmed by the whitish coloration of eyes, lack of spontaneous breathing, and lack of reflex to the pain. The skin where the healing process was found was removed using surgical scissors, and samples were included in $10 \%$ formaldehyde to maintain morphological characteristics.

\section{HISTOLOGY}

After euthanasia, skin samples were removed and placed in $10 \%$ formalin. Samples were identified using codes with specific numbers in each flask. These samples were sent to the Histocenter - Guarapuava laboratory with an encoded identification (ex: X1,X2); $2 \mu \mathrm{m}$ thick histological sections from the medial region to the edges were embedded in paraffin. Three histological sections were cut from each piece. These were stained with Hematoxylin-Eosin for the cellular and pathological analyses.

\section{ANALYSIS BY POLARIZED LIGHT}

Slides stained with Picrosirius Red were observed in an Olympus BX50 microscope. Images were captured using a Dinoeye $30 \mathrm{~mm}$ CCD, Olympus U-POT polarizer, photographed at 400X, and saved in the Dinocapture software at 1024-1280 resolution. The Image-Pro Plus $4{ }^{\circledR}$ software was used to analyze the percentage of mature and immature collagen.

\section{WOUND SIZE ASSESSMENT}

Contraction is the reduction of part or all open wounded area, occurring centripetally from the edges of the lesion Cook (2011) and caused by actin filaments ${ }^{16}$ from myofibroblasts and the rearrangement of collagen molecules Kerppers et al. (2015).

All animals were photographed daily with the aid of a Fujifilm Finepix 3200, 10.0 Megapixels digital camera, without zoom approximation, and kept on a tripod at 20 $\mathrm{cm}$ from the animal. These images were transferred to a computer where lesions were observed.

\section{IMMUNOHISTOCHEMISTRY (IHC)}

Slides were prepared to contain two sections per slide, per experimental group, and as described in the histological analysis. Thermal dewaxing was performed for 16 hours in an oven at $60{ }^{\circ} \mathrm{C}$. Subsequently, chemical dewaxing was performed 
through two 10-minute immersion baths in Xylol, and one 10 -minute $70^{\circ}$ alcohol immersion bath. After one water bath, slides were immersed in Sodium Citrate and subsequently placed in a 30-minute water bath for antigenic recovery.

Field markings were performed as described by Panis Panis et al. (2011); the sections were delimited with a Dako Pen ${ }^{\circledR}$ hydrophobic pen. Endogenous peroxidases were blocked in $10 \%$ hydrogen peroxide solution for 30 minutes, followed by nonspecific bond blocking incubation in $0.1 \%$ fetal serum for 1 hour.

Subsequently, sections were incubated with primary antibodies (Santa Cruz Biotech) anti-TGF- $\beta 1$ (1:300) and anti-VEGF- $\alpha$ (1:300) in an overnight humid chamber at $4{ }^{\circ} \mathrm{C}$. After this incubation, slides were submitted to 3 baths ( 5 minutes each) in PBS and incubated with secondary antibodies for 15 minutes. One PBS jet wash was followed by three PBS drop washes.

Markings were revealed by incubation in 3.30-diaminobenzidine (DAB) for 15 minutes, followed by two PBS washes, the first as a jet wash, and the second as a drop wash. In the last stage, sections were slightly counter colored with Harry's hematoxylin (Merck) for 30 seconds and washed under running water.

Incubated in alcohol $70^{\circ}$ by 5 minutes in an immersion bath. Incubated in $95^{\circ}$ alcohol by 5 minutes in an immersion bath. Incubated in Xylol for 5 minutes and incubated again in Xylol for 10 minutes. After draining all the liquid, the slides were assembled with Canadian balsam and coverslips.

The primary antibody was removed by washing the slides in PBTD 3 times in room temperature for 10 minutes each. Excess PBTD was drained, slides were returned to the humid chamber and 200-300 microliters of diluted secondary antibody was added. The samples were incubated at room temperature for 1-2 hours. The secondary antibody was removed by washing the slides in PBTD 3 times at room temperature for 10 minutes each. As much PBTD as possible was drained from the slide and a drop of Vectashield was added directly to the sections.

Negative controls were prepared in serial sections for all treatments. The intensity and location of the immunoreactivity to all used primary antibodies were examined throughout the content of each slide using an optical microscope. As a negative control, the primary antibody was omitted. The image analysis study digitally acquired color photomicrographs of representative areas (40x magnification). A total of 10 images were taken from each slide of each animal and evaluated using the color deconvolution tool in Image J software (NIH, USA), receiving semi-quantitative scores. Pixels were categorized as strong positive $(3+)$, positive $(2+)$, weak positive $(1+)$, and negative (0), as previously described in Chatterjee et al Chatterjee et al. (2013).

\section{STATISTICAL ANALYSIS}

The Graph Pad Prism 7.0 program was used for the statistical analyses. The Shapiro Wilk test was applied to verify sample normality. The data were analyzed using the Kruskal-Wallis test, followed by Dunn's Test. Differences with a value of $\mathrm{p}<0.05$ were considered significant. 


\section{RESULTS AND DISCUSSIONS}

\section{HISTOLOGICAL ANALYSIS}

Figure 1 shows histological sections (40X magnification) stained with hematoxylin-eosin (HE) from the Control Group (CG) and LED Group (LG) in all subgroups (after 3, 7, 14, and 21 days of treatment).

The lesions are characterized with an acute to a subacute inflammatory process, alterative-erosive inflammation type, typical of lining epithelia. The inflammation is shown in a diffuse distribution with variable intensity according to the treatment period.

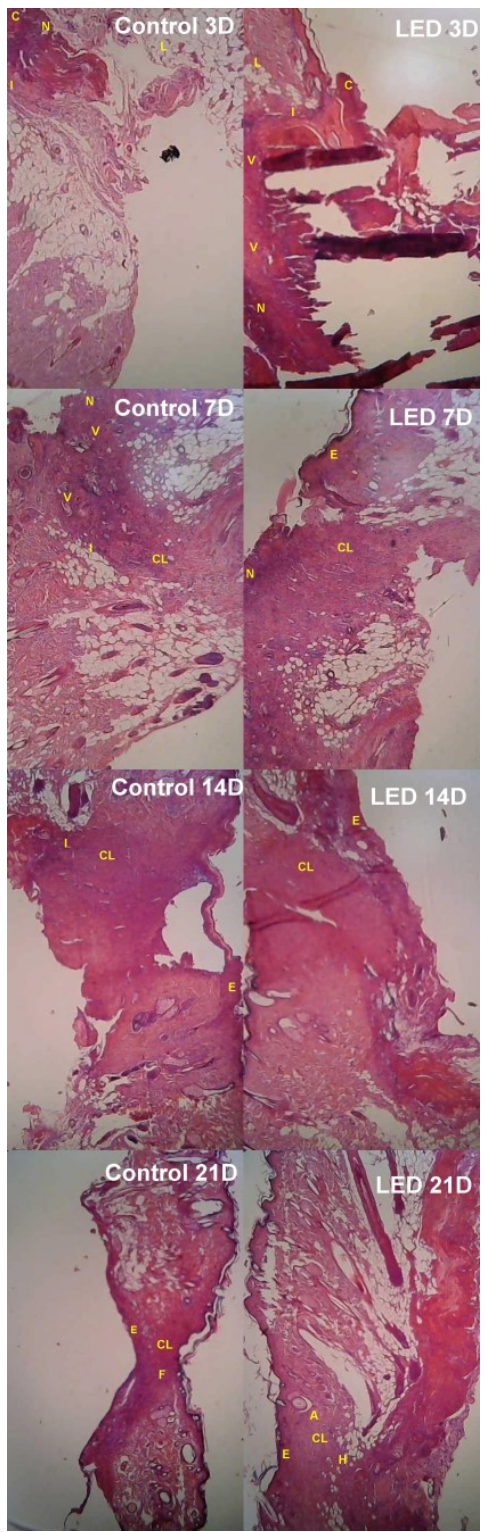

Figure 1 Histological analysis at 40x magnification following 3, 7, 14, and 21 days of treatment 
On treatment day 3, in subgroup C3 intense necrosis $(\mathrm{N})$ is observed in the region of the lesion, with the presence of a crust (C), and an intense inflammatory process (I) with the intense presence of mononuclear and polymorphonuclear cells, with large groups of lipid cells (L). In subgroup L3, intense necrosis (N) is also observed, as well as the presence of epidermal crust throughout the lesion (C), although there are smaller clusters of lipid cells (L), and a moderate inflammatory process with polymorphonuclear cells (I), moderate presence of mononuclear cells at the base of the lesion, as well as intense neovascularization below the lesion (V).

On treatment day 7, C7 presents mild tissue necrosis $(\mathrm{N})$, moderate neovascularization (V), moderate inflammatory (I) process with polymorphonuclear characteristics, absence of epidermis (Ea) and distribution of collagen (CL) with irregular shape at the base of the lesion. In L7, hyperplastic epidermis (Eh), moderate collagen (CL) deposition at the edges of the lesion and a small necrotic tissue in the upper left edge were observed.

After 14 days of treatment, in C14 there is still a mild inflammatory (I) process at the edges of the lesion, collagen (CL) appears more regularly in the dermal region and hyperplastic epidermis at the edges of the lesion. In L14, the epidermis (E) has closed completely over the dermis, and collagen (CL) is regularly distributed in the dermis region.

On treatment day 21, in C21, the formation of the epidermis (E), collagen distributed regularly (CL) and closure (F) of the lesion in the dermis region were observed. L21 presented complete restructuring of the epidermis (E) in all its layers, collagen (CL) presented normal distribution and was interlaced in the dermis region, with attachments (A) in the dermal region. The hypodermic layer was completely reorganized $(\mathrm{H})$.

\section{POLARIZED LIGHT ANALYSIS}

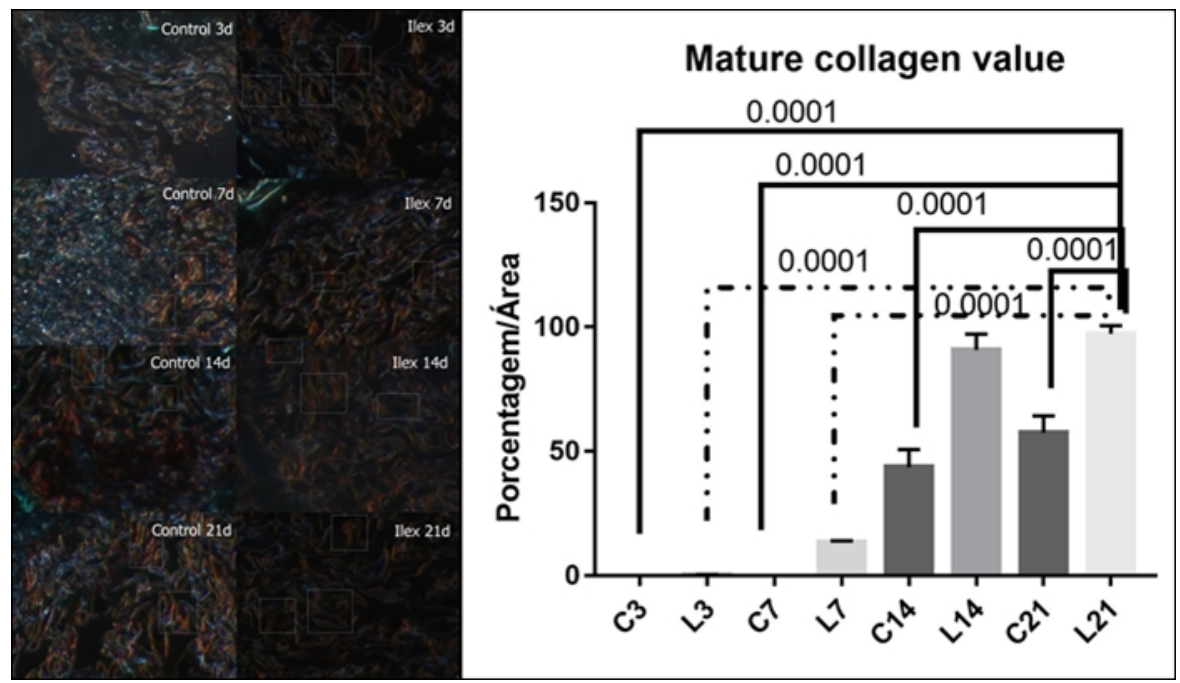

Figure 2 Polarized light analysis on treatment day 3, 7, 14, and 21, presented as means and SD in mature collagen quantitative analysis 
Figure 2 shows the analysis of mature collagen present in the lesion using Picrosirius Red. Birefringence shows mature collagen in red coloration and immature collagen in greenish coloration. LED-treated groups presented the highest amount of mature collagen on treatment days 14- and 21.

This quantitative analysis for mature collagen showed mean values and SD for the subgroups: C3, L3, C7, L7, C14, L14, C21 and L21, respectively $0.0 \pm 0.0 ; 0.25 \pm 0.19$; $0.01 \pm 0.0 ; 13.5 \pm 0.52 ; 43.67 \pm 7.15 ; 90.75 \pm 6.45 ; 57.50 \pm 6.78$ and $97.25 \pm 3.25$.

It was noted that the L21 group showed a mean value for collagen deposition $51.54 \%$ higher than the C21 group.

The figure shows the statistical differences between C3/L21 ( $\mathrm{p}=0.0001) ; \mathrm{C} 7 / \mathrm{L} 21$ $(\mathrm{p}=0.0001) ; \mathrm{C} 14 / \mathrm{L} 21(\mathrm{p}=0.0001), \mathrm{C} 21 / \mathrm{L} 21(\mathrm{p}=0.0001), \mathrm{L} 3 / \mathrm{L} 21 \quad(\mathrm{p}=0.0001)$ and C14/L21 ( $\mathrm{p}=0.0001)$.

\section{WOUND CONTRACTION ANALYSIS}

Figure 3 shows the macroscopic analysis of wound contraction in CG and LG subgroups on treatment days 3, 7, 14, and 21. L14 and L21 group showed complete epidermal regeneration, without any scar remnants after 21 days of treatment. C21 showed incomplete regeneration. The graph shows the mean and SD values for the contraction of the lesion diameter. Significance is observed between the subgroups C7/L14 ( $p=0.0155) ;$ C7/L21 ( $p=0.0130)$ and C21/L21 ( $p=0.274)$.

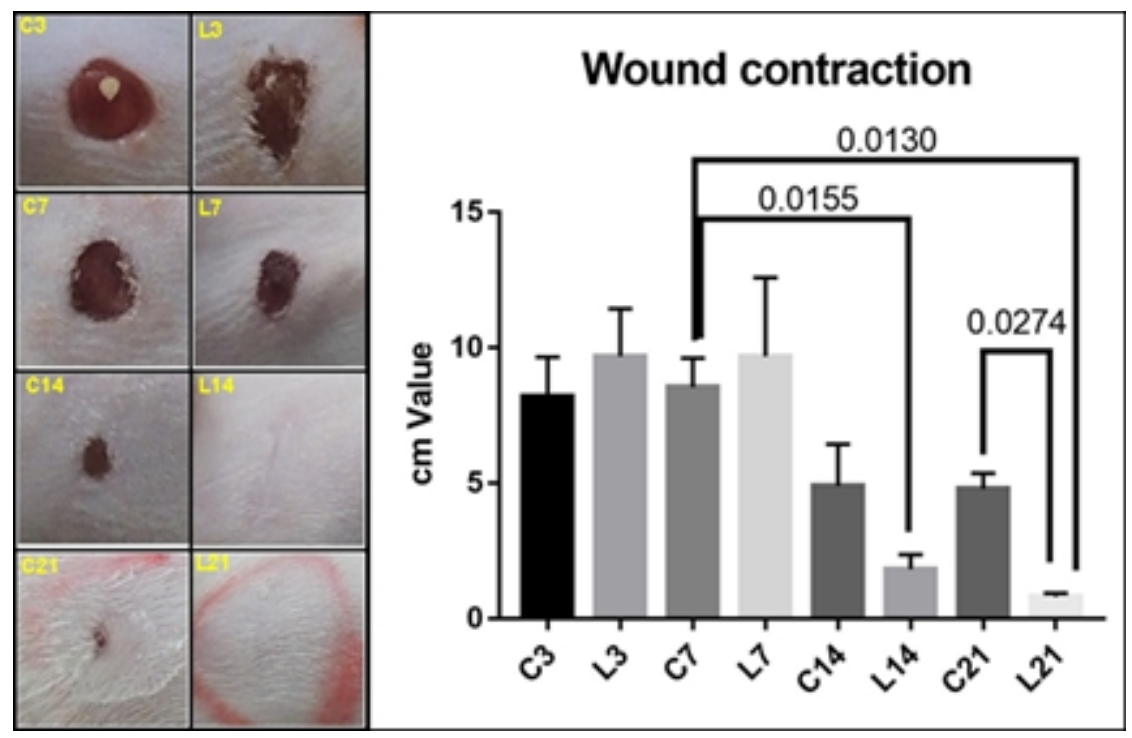

Figure 3 Wound contraction on treatment day $3,7,14$, and 21

\section{IMMUNOHISTOCHEMISTRY}

VEGF- $\alpha$ expression increased 9\% in L3 group compared to the C3, the mean values were $2.2 \pm 0.4$ and $2.4 \pm 0.5$, respectively; although L7, L14 and L21 VEGF- $\alpha$ values decreased, 1.8, 1.4 and 0.4; while control group values showed an increase (C7=2 and C21=2.8). Statistical analysis showed a significant difference between C3/L21

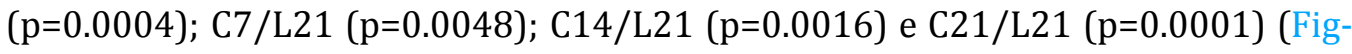


ure 2 ).

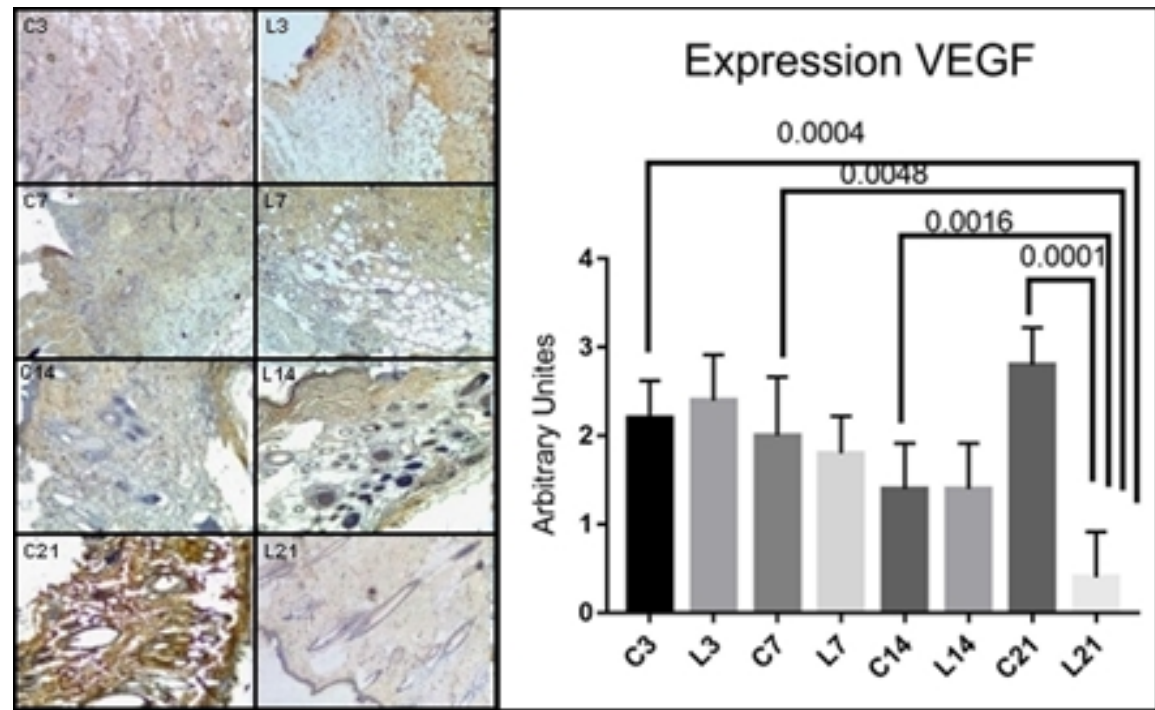

Figure 4 Differences in the expression of VEGF between LED and control groups

Transforming growth factor (TGF- $\beta 1$ ) decreased in all LED groups in relation to control groups with $\mathrm{p}<0.0001, \mathrm{~F}(2.78,30.66)$. Tukey's multiple comparisons test showed significant differences between LED groups in relation to their controls, i.e., C3/L3 ( $p=0.0148)$, C3/L7 ( $p=0.0056), C 3 / 114$ ( $p=0.0001), C 3 / L 21$ ( $p=0.0001)$, C7/L21 ( $\mathrm{p}=0.0001)$ and C14/L21 (p=0.0148) (Figure 2$)$.

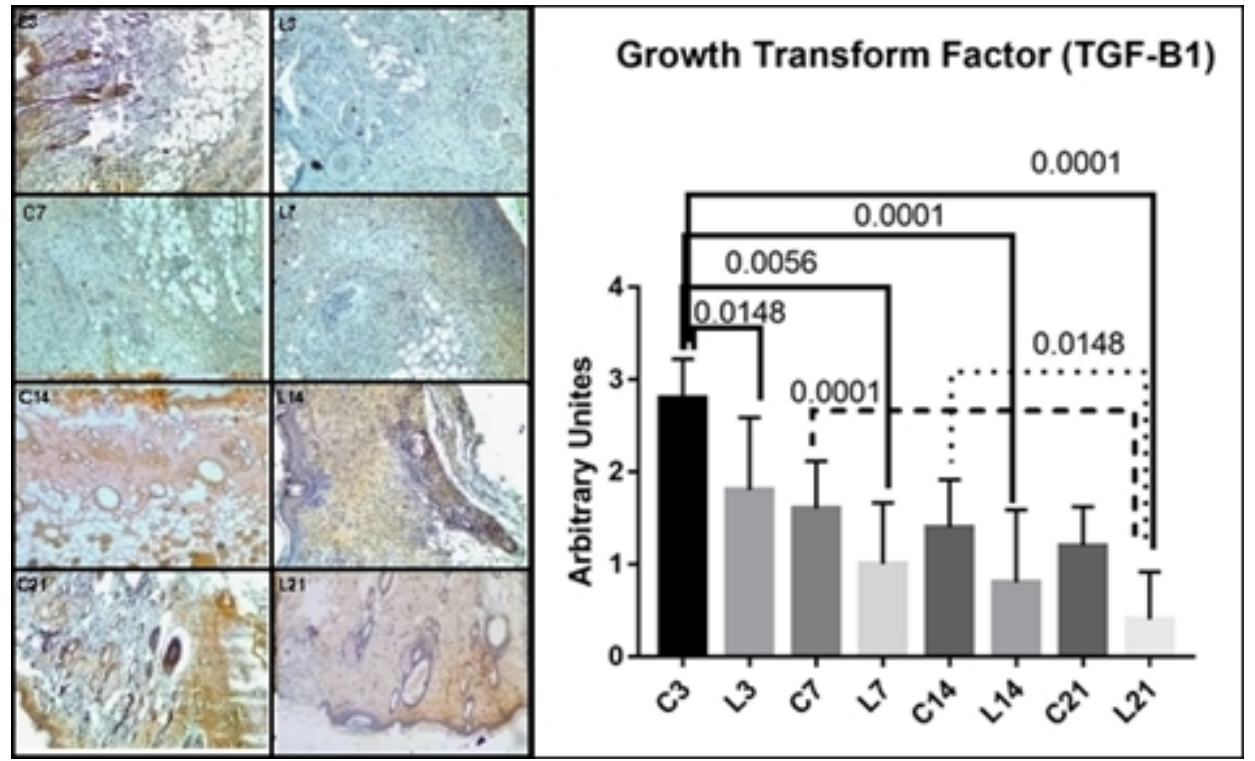

Figure 5 Differences in the expression of TGF- $\beta 1$ between LED and control groups 
The use of LED as a light source has been studied due to the advantages shown along with its low costs, practicality and low energy consumption Havel et al. (2014). Although different studies have approached LED treatments, there still is not a consensus on the ideal treatment parameters, as well as the knowledge of all the mechanisms involved Vieira et al. (2020). In face of these differences, in this study the influence of LED $627 \mathrm{~nm}$ on the expression VEGF- $\alpha$ e TGF- $\beta 1$ treatment on the healing of second intention wounds was evaluated.

Kerppers and collaborators Kerppers et al. (2015) evaluated the influence of 627 and $945 \mathrm{~nm}$ LED irradiation on collagen replacement during wound healing. $627 \mathrm{~nm}$ LED treatment was irradiated for 100 seconds, and $945 \mathrm{~nm}$ LED for 63 seconds, both with doses of $7 \mathrm{~J} / \mathrm{cm}^{2}$. Their results showed the presence of refringence, only on the lateral edges of the lesion, on the third day in the control group, and the presence of immature collagen at the lesion site on the seventh day, which is characteristic greenish in color. Kerppers and collaborators Kerppers et al. (2015) further demonstrated the presence of mature collagen in all groups on the seventh day, reflecting values greater than those observed on the third day. The identified averages and standard deviations were GC (59.3 \pm 4.9$)$; GL67 (75.0 \pm 12.0$)$.

In the present study, the LED group did not present large amounts of type I collagen on treatment days 3 and 7; however, it showed increased amounts after 14 and 21 days of treatment, indicating similar effects to those in the physiological system of wound healing. However, the present study differs from Kerppers and collaborators Kerppers et al. (2015) in the lesion model used, which evaluated primary intention wound healing while the present study evaluated the effects of LED on secondary intention wound healing.

Adamskaya and collaborators Adamskaya et al. (2011) compared the effects of blue LED light (470 $\mathrm{nm}$ ), red LED light ( $630 \mathrm{~nm}$ ), and control groups (no LED irradiation) on wound healing in rats; LED treatments were performed for 7 consecutive days, for 10 minutes, with an intensity of $50 \mathrm{~mW} / \mathrm{cm}^{2}$. The analyses after 7 days of treatment showed that both LED treatments substantially influenced the wound healing process and interfered in the RNA expression. Our results, on the other hand, showed that $627 \mathrm{~nm}$ increased collagen deposition, with shorter exposure time that that used by Adamskaya et al Adamskaya et al. (2011) i.e., 63 seconds compared to 10 minutes, but by using with a higher irradiance $\left(70 \mathrm{~mW} / \mathrm{cm}^{2}\right.$ compared to 50 $\mathrm{mW} / \mathrm{cm}^{2}$ ). Therefore, the potentiating factor may be relevant to the process of cellular stimulation.

In the present study, the effect of the red LED $(627 \mathrm{~nm})$ was evaluated in epidermal wounds through histological and macroscopic analyses. The protocol used was different from those reported by Adamskaya and collaborators. However, the findings corroborate the beneficial effects on the control of the inflammatory process, re-epithelialization of wound edges, and wound healing; as histologically, a complete closure of the epidermis was observed after 14 days of treatment, in addition to a regular distribution of collagen compared to the control group, as observed 21 days after 
the injury.

Analysis of Picrosirius Red showed that deposition of mature collagen occurred from the third day of treatment on, with concentrations increasing throughout the treatment and showing complete deposition after 21 days of treatment. Regularity and complete wound closure were observed on treatment day 14 in LED-treated group, with the appearance of normal dermis indicating the acceleration of the collagen deposition and healing process provided by LED.

Ghaemi and collaborators Ghaemi et al. (2019) reported that epidermal formation was in the process of completion after 30 days of treatment with red LED irradiation. However, a large amount of scar tissue could be seen. A severe inflammatory reaction was detected in the wound. Thus, it can be said that the present study provided tissue repair (healing) in less time than that reported by Ghaemi and collaborators Ghaemi et al. (2019) who used the dose of $30 \mathrm{~J} / \mathrm{cm}^{2}$ - while the present study used only 7 $\mathrm{J} / \mathrm{cm}^{2}$.

Singer and Clark Singer and Clark (1999) report in their study that macrophages produce several growth factors, such as PDGF, TGF- $\beta$, fibroblast growth factor (FGF) and VEGF, which stand out as the main necessary cytokines to stimulate the formation of granulation tissue.

Este relato assemelha-se ao estudo proposto onde pode-se notar diferença entre o C3 e L3 na presença de células mononucleares e polimorfonucleares o que justifica o aumento de VEGF- $\alpha$ no L3.

The results presented herein extend literature data and demonstrate that $627 \mathrm{~nm}$ LED irradiation effectively accelerated wound healing increasing the levels of VEGF$\alpha$ and TGF- $\beta 1$ in the initial phase, leading complete healing in 14 days, a shorter time when compared to unassisted physiological healing of the control group.

Martignago and collaborators Martignago et al. (2020) carried out a study in which skin grafts were irradiated daily for ten consecutive days, starting immediately after the surgery, using a red $(630 \mathrm{~nm})$ or near infrared $(850 \mathrm{~nm})$ LED. The results showed that the red wavelength LED significantly enhanced the skin graft score in relation to the NIR group and increased the expression of TGF- $\beta$ and the density of collagen fibers compared with the other experimental groups. These results suggest that the red wavelength LED was efficient in improving dermo-epidermal junction and modulating the expression of proteins related to tissue repair.

In this study, TGF- $\beta$ levels increased between 3 and 14 days of treatment; however, it decreased after 21 days of treatment. This result is explained by the fact that the wounds are already closed on the 14 th. TGF- $\beta$ is involved in amplifying the migration of inflammatory cells, in stimulation of angiogenesis, formation of granulation tissue and reepithelization, in addition to stimulating collagen deposition Campos et al. (2007), in line with what was observed in the present study, where there was an increase in collagen deposition after expression of TGF- $\beta$. 


\section{CONCLUSIONS AND RECOMMENDATIONS}

It was concluded that therapy with LED $627 \mathrm{~nm}$ for 100 seconds at a dose of $7 \mathrm{~J} / \mathrm{cm}^{2}$ was able to accelerate the healing process, having an effect associated with the influence on the expression of VEGF- $\alpha$ and TGF- $\beta 1$. The irradiation led to effective results in wound regeneration and related to vascular, exudative, and proliferative phenomena, as well as increased collagen deposition in the treated groups.

\section{REFERENCES}

Adamskaya, N., Dungel, P., Mittermayr, R., Hartinger, J., Feichtinger, G., Wassermann, K., Redl, H., \& van Griensven, M. (2011). Light therapy by blue LED improves wound healing in an excision model in rats. Injury, 42(9), 917-921. Retrieved from https:// dx.doi.org/10.1016/j.injury.2010.03.023 10.1016/j.injury.2010.03.023

Alerico, G. C., Beckenkamp, A., Vignoli-Silva, M., Buffon, A., \& von Poser, G. L. (2015). Proliferative effect of plants used for wound healing in Rio Grande do Sul state, Brazil. Journal of Ethnopharmacology, 176, 305-310. Retrieved from https://dx.doi.org/10.1016/ j.jep.2015.11.001 10.1016/j.jep.2015.11.001

Barrientos, S., Stojadinovic, O., Golinko, M. S., Brem, H., \& Tomic-Canic, M. (2008). Growth Factors And Cytokines In Wound Healing. Wound Repair Regen, 5, 585-601.

Campos, A., Borges-Branco, A., \& Groth, A. K. (2007). Cicatrização De Feridas. Arq Bras Cir Dig (Vol. 1).

Chatterjee, S., Malhotra, R., Varghese, F., Bukhari, A. B., Patil, A., Budrukkar, A., Parmar, V., Gupta, S., \& De, A. (2013). Quantitative Immunohistochemical Analysis Reveals Association between Sodium Iodide Symporter and Estrogen Receptor Expression in Breast Cancer. PLoS ONE, 8(1), e54055-e54055. Retrieved from https://dx.doi.org/10.1371/ journal.pone.0054055 10.1371/journal.pone.0054055

Cook, L. (2011). Wound Assessment: Exploring Competency And Current Practice. Br J Community Nurs, 12, 34-40.

De, J. S. A. M., \& Martins, G. B. (2019). Utilização Do Diodo Emissor De Luz (Led) Na Cicatrização De Queimaduras: Revisão Sistemática Da Literatura. Rev Pesq Fisio, 1, 108-127.

de Alencar Fernandes Neto, J., Nonaka, C. F. W., \& de Vasconcelos Catão, M. H. C. (2019). Effect of blue LED on the healing process of third-degree skin burns: clinical and histological evaluation. Lasers in Medical Science, 34(4), 721-728. Retrieved from https://dx.doi .org/10.1007/s10103-018-2647-x 10.1007/s10103-018-2647-x

dos Santos, K. M. M. G., Cordeiro, M. E. R., da Silva Pereira, M. C., Barbosa, D., Pezzini, A. A., \& Kerppers, I. I. (2020). Comparative study in photodynamic therapy using the same photosensitizer in tissue repair after second-degree burns in an experimental model. Lasers in Dental Science, 4(1), 17-24. Retrieved from https://dx.doi.org/10.1007/ s41547-019-00081-8 10.1007/s41547-019-00081-8

Ghaemi, M., Sharifi, D., Mokmeli, S., Kowsari, G., Mortazavi, P., \& Golmai, P. (2019). Comparison and Evaluation of the Low-Level Laser and the Red and Blue LED Effects on Wound Healing in Rabbit. Journal of Lasers in Medical Sciences, 10(3), 189-193. Retrieved from https://dx.doi.org/10.15171/jlms.2019.30 10.15171/jlms.2019.30

Havel, M., Betz, C. S., Leunig, A., \& Sroka, R. (2014). Diode laser-induced tissue effects: In vitro tissue model study and in vivo evaluation of wound healing following non-contact application. Lasers in Surgery and Medicine, 46(6), 449-455. Retrieved from https:// 
dx.doi.org/10.1002/lsm.22256 10.1002/lsm.22256

Isaac, C., de Ladeira, P. R. S., do Rêgo, F. M. P., Aldunate, J. C. B., \& Ferreira, M. C. (2010). Processo de cura das feridas: cicatrização fisiológica. Revista de Medicina, 89(3/4), 125125. Retrieved from https://dx.doi.org/10.11606/issn.1679-9836.v89i3/4p125-131 10.11606/issn.1679-9836.v89i3/4p125-131

Kerppers, I. I., de Lima, C. J., Fernandes, A. B., \& Villaverde, A. B. (2015). Effect of light-emitting diode $(\lambda 627 \mathrm{~nm}$ and $945 \mathrm{~nm} \lambda)$ treatment on first intention healing: Immunohistochemical analysis. Lasers in Medical Science, 30(1), 397-401. Retrieved from https:// dx.doi.org/10.1007/s10103-014-1668-3 10.1007/s10103-014-1668-3

Kim, C. H., Cheong, K. A., \& Lee, A. Y. (2013). 850nm Light-Emitting-Diode Phototherapy Plus Low-Dose Tacrolimus (FK-506) As Combination Therapy In The Treatment Of Dermatophagoides Farinae-Induced Atopic Dermatitis-Like Skin Lesions In NC/Nga Mice. J. Dermatol. Sci, 2, 142-150.

Martignago, C. C. S., Tim, C. R., Assis, L., Silva, V. R. D., Santos, E. C. B. D., Vieira, F. N., Parizotto, N. A., \& Liebano, R. E. (2020). Effects of red and near-infrared LED light therapy on full-thickness skin graft in rats. Lasers in Medical Science, 35(1), 157-164. Retrieved from https://dx.doi.org/10.1007/s10103-019-02812-6 10.1007/s10103-019-02812 $-6$

Mendonça, R. J., De, Coutinho-Netto, J., \& Cicatrização, A. C. D. (2009). An Bras Dermatol, 3, 257-62.

Otterço, A. N., Brassolatti, P., Andrade, A. L. M., Avó, L. R. S., Bossini, P. S., \& Parizotto, N. A. E. (2018). Effect of photobiomodulation $(670 \mathrm{~nm})$ associated with vitamin $A$ on the inflammatory phase of wound healing. Lasers in Medical Science, 33(9), 1867-1874. Retrieved from https://dx.doi.org/10.1007/s10103-018-2535-4 10.1007/s10103 -018-2535-4

Panis, C., Mazzuco, T. L., Costa, C., Victorino, V. J., Tatakihara, V., Yamauchi, L. M., \& Al, E. (2011). Trypanosoma Cruzi: Effect Of The Absence Of 5-Lipoxygenase (5-LO)-Derived Leukotrienes On Levels Of Cytokines, Nitric Oxide And Inos Expression In Cardiac Tissue In The Acute Phase Of Infection In Mice. Exp. Parasitol, 1, 58-65.

Patrulea, V., Ostafe, V., Borchard, G., \& Jordan, O. (2015). Chitosan as a starting material for wound healing applications. European Journal of Pharmaceutics and Biopharmaceutics, 97, 417-426. Retrieved from https://dx.doi.org/10.1016/j.ejpb.2015.08.004 10.1016/j.ejpb.2015.08.004

Singer, A. J., \& Clark, R. A. (1999). Cutaneous Wound Healing. New England Journal of Medicine, 341(10), 738-746. Retrieved from https://dx.doi.org/10.1056/ nejm199909023411006 10.1056/nejm199909023411006

Singh, K., Agrawal, N. K., Gupta, S. K., Sinha, P., \& Singh, K. (2016). Increased expression of TLR9 associated with pro-inflammatory S100A8 and IL-8 in diabetic wounds could lead to unresolved inflammation in type 2 diabetes mellitus (T2DM) cases with impaired wound healing. Journal of Diabetes and its Complications, 30(1), 99-108. Retrieved from https://dx.doi.org/10.1016/j.jdiacomp.2015.10.002 10.1016/j.jdiacomp.2015 .10 .002

Vieira, A. B. H., Purificação, M. B., Ferreira, M. D. F., Costa, T. D. C. D., Lam, Y. W., Ramos, F. S., \& Gante, R. D. S. (2020). Os efeitos fisiológicos do led vermelho no tegumento. Revista Científica de Estética e Cosmetologia, 1(1), 28-38. Retrieved from https://dx.doi.org/ 10.48051/rcec.v1i1.22 10.48051/rcec.v1i1.22 